Brit. J. industr. Med., 1963, 20, 300.

\title{
AN EXPERIMENT IN FILM READING
}

\author{
BY \\ F. D. K. LIDDELL \\ From the Medical Statistics Branch of the National Coal Board
}

(RECEIVED FOR PUBLICATION MARCH 10, 1963)

In a first trial of an experimental classification of simple pneumoconiosis, each observer was asked to record, for each reading, not only the (I.L.O.) category into which he would have placed the radiograph but also whether he had seriously considered placing it in an adjacent category. Three skilled readers took part in the experiment, in which 120 films (consisting of three, taken in 1949 , 1952, and 1956, for 40 subjects who had been at one colliery throughout the period) were read independently by each reader on two occasions and, subsequently, in a joint reading session. Despite the element of arbitrariness in the definition of when an alternative category should be recorded, the proportion of films for which alternates were quoted was very similar (just about half) for all three readers.

Complete agreement in the finer classification which is produced with the experimental method of reading was naturally less common than when conventional categorization was considered. However, when account was taken of the extent of the disagreements, both intra-observer error and inter-observer error were found to be considerably reduced in the experimental classification.

In studying the progression of pneumoconiosis in the subjects' films from one survey to another, it was found that there was an apparent understatement of progression when the conventional classification was adopted. This arose because, where both films for one subject were placed in the same (I.L.O.) category, there was a considerable tendency for progression to be indicated by a change in the categorization according to the experimental classification.

\section{Introduction}

New problems of reading chest radiographs for pneumoconiosis were introduced when the scheme of periodic $x$-ray examination for 550,000 British coal-miners was brought into operation by the National Coal Board at the end of 1958 (see the Annual Reports of the Board's Medical Service for 1957 to 1961). The rate of production of films per full-time reader, about 15,000 a year, is very high; it is, for example, more than six times as great as in the Board's Pneumoconiosis Field Research Scheme (Fay, 1957). This means that in general each film can be read once only by one reader, whereas in most other schemes either multiple or joint readings are feasible. Further, one of the most important long-term objects of the Board's Periodic $X$-ray Scheme is to function as a biological control of airborne dust, i.e. to monitor dust suppression methods at each individual colliery in terms of the progression of pneumoconiosis in the mining population at that colliery. We therefore wished to examine methods of reading radiographs for pneumoconiosis to try to determine the most suitable method from the points of view of this particular scheme. This paper describes the results of one experiment in the reading of simple pneumoconiosis.

The evolution of the various classifications of pneumoconiosis has been described by Van Mechelen and McLaughlin (1962). As far as simple pneumoconiosis is concerned, the basic classification has been, since 1950 , into four categories $(0,1,2$ or 3$)$, although some (varying) provisions have been made for the recording of the type of opacities present, e.g. nodular or pin-head. It is, however, generally accepted that the radiological appearances of simple pneumoconiosis form a continuum, and the writer has noticed that most readers of his acquaintance frequently talk of films in such terms as "high 2" or "low 1". This suggests that, if the readers' comments could be codified and made use of, a finer classification should be possible with a consequent improvement in sensitivity.

An experiment was therefore designed to investigate the possibilities of codification, yet without 
conflicting with existing methods. Three experienced readers (Dr. J. C. Gilson, Director of the Medical Research Council's Pneumoconiosis Research Unit in South Wales; Dr. W. E. Miall, then a member of the same Unit; and Dr. P. J. Chapman, the Medical Officer in charge of one of the National Coal Board's Medical Research Units) co-operated in the experiment, which is reported here.

\section{Choice of Films}

A total of 120 films was chosen for this study. They consisted of three films, taken respectively in 1949 , in 1952, and in 1956, for each of 40 subjects who had been employed at Bank Hall colliery, Lancashire, throughout the period. The $\mathbf{4 0}$ subjects were chosen from among the 260 men who had been radiographed on each of the three occasions (excluding those in whom progressive massive fibrosis had been diagnosed), as indicated in Table 1; within each

TABLE 1

CHOICE OF SUBJECTS

\begin{tabular}{c|c|c|c}
\hline N.C.B. Definitive Reading of & \multicolumn{2}{|c}{$\begin{array}{c}\text { No. of Men with this Combin- } \\
\text { ation of Readings }\end{array}$} \\
\hline 1949 Film & 1956 Film & In Population & In Sample* \\
\hline 0 & 0 & 139 & 8 \\
0 & 1 & 38 & 10 \\
0 & 2 & 29 & 7 \\
0 & 3 & 4 & 1 \\
1 & 0 & 3 & 1 \\
1 & 1 & 9 & 2 \\
1 & 2 & 2 & 1 \\
1 & 3 & 6 & 2 \\
2 & 2 & 3 & 1 \\
2 & 3 & 15 & 4 \\
\hline 3 & 3 & 260 & 40 \\
\hline
\end{tabular}

*The sampling fraction was 1 in 4 except for men with normal films in both 1949 and 1956.

$\dagger$ No combination of readings other than those listed above was observed, except of men diagnosed as having P.M.F.

combination of $x$-ray categories listed in that table, the subjects to be included in the sample were chosen by means of random numbers.

The 120 films were arranged for reading in a single random order. Thus, the three films for any one subject might appear in any order within the series. All three readers read the films independently on two occasions each, and subsequently they all took part in a joint reading session. The films were also read on one occasion by the writer, for whom it was the first formal experience of film reading.

\section{Method of Reading}

Each reader was asked to record not only the (I.L.O., 1953) category into which he would have placed the film following the normal convention [called in this paper the "formal" category], but also whether he had, in the course of that categorization, seriously considered placing it in an adjacent category. The results were recorded by entering the "formal" category followed by a stroke and either (a) the alternative category considered or (b) a dash to indicate that, in the reader's view, the film was clearly within the (I.L.O.) category and no alternative had been seriously considered. For example, the symbol $1 / 2$ would mean that the film was formally placed in category 1 but that it was sufficiently close to the boundary of category 2 for that category to have been a real alternative reading; many readers would call such a film a "high 1". The symbol 0/0 was used for "barn-door" normals, i.e. films over which the reader had no trace of doubt that they were normal, as distinct from $0 /-$, implying rather less confidence that the appearances were normal, while $0 / 1$ indicates that category 1 was under serious consideration as an alternative. At the other extreme of the continuum, the symbol $3 / 3$ was used for a film showing evidence of so much dust that the reader considered there could be no doubt that it would always be read as category 3 . The experimental classification is illustrated in Fig. 1.

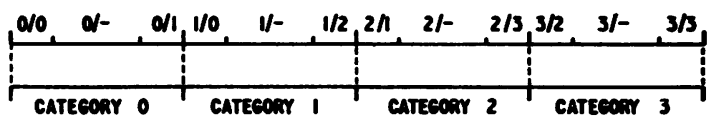

Fig. 1.-The experimental classification.

One reader (C) followed the instructions very closely; in two cases, one in each session, he actually recorded as serious alternatives both categories adjacent to the "formal" category, e.g. 1/(0 and 2). These two readings have been excluded from the data examined below. In discussion with the other readers after their sessions it appeared that there may have been a tendency for them to define sub-categories for themselves. In any case, it seems likely that in those cases where no alternatives were recorded the radiological appearances were considered by the individual reader as falling in a central zone within the appropriate I.L.O. category. A first assessment of the width of these central zones can be made in terms of the distribution of the readings, which are given for all three readers in Table 2 . This shows that in each of the categories 0,1 , and 2 the proportion of readings in the central zone was close to $50 \%$. The comparatively high proportion in the central zone in category 3 arises largely because reader $\mathrm{C}$ did not in practice make use of the class $3 / 3$; for readers $\mathbf{A}$ and $\mathbf{B}$, who did use this class, the proportion in the central zone was 32 out of $56(57 \cdot 1 \%)$. 
TABLE 2

DISTRIBUTION OF READINGS

\begin{tabular}{|c|c|c|c|}
\hline & Reading & Frequency & $\begin{array}{l}\text { Proportion } \\
\text { in "Central Zone" }\end{array}$ \\
\hline Category 0 & $\begin{array}{l}0 / 0 \\
0 /- \\
0 / 1\end{array}$ & $\begin{array}{rr}59 & \\
193 & \\
115 & \\
& 367\end{array}$ & $193 / 367(52 \cdot 6 \%)$ \\
\hline Category 1 & $\begin{array}{l}1 / 0 \\
1 / 2 \\
1 / 2\end{array}$ & $\begin{array}{ll}49 & \\
63 & \\
29 & \\
- & 141\end{array}$ & $63 / 141(44 \cdot 7 \%)$ \\
\hline Category 2 & $\begin{array}{l}2 / 1 \\
2 /- \\
2 / 3\end{array}$ & $\begin{array}{ll}27 & \\
68 & \\
31 & \\
- & 126\end{array}$ & $68 / 126(54 \cdot 0 \%)$ \\
\hline Category 3 & $\begin{array}{l}3 / 2 \\
3 /- \\
3 / 3\end{array}$ & $\begin{array}{l}14 \\
54 \\
16 \\
-\quad 84 \\
\end{array}$ & $54 / 84(64 \cdot 3 \%)$ \\
\hline
\end{tabular}

With this one exception, the three readers were fairly consistent in placing about half the films in each category within the central zone.

The widths of these central zones might be expected to depend on the reader's experience and confidence: it would seem not unlikely that the least experienced would tend to equivocate, quoting an alternative in a high proportion of cases and so leaving only small central zones, while the most experienced would tend to quote alternatives only in comparatively rare cases of doubt, leaving a wide central zone in each category. It is, therefore, of interest that the inexperienced reader also placed just about half the films $(52.9 \%)$ in the central zones of the four categories.

Thus, it seems reasonable as a first approximation to treat the width of the central zone of each (I.L.O.) category as about half a (I.L.O.) category and for the marginal zones each to be treated as a quarter (I.L.O.) category wide. Fortunately, the exact widths of the zones have no material effect on the interpretation of the results, provided each zone can be taken as a roughly constant proportion of the complete category and central within the category. Although this assumption is probably not fully justified, it appears reasonable and unlikely to lead to major errors. Further, when, in what follows, observer error is quantified, the assumption does not affect the measures (of information; see Appendix) obtained.

\section{Theoretical Effect of the Experimental Classific- ation on Observer Error}

When two sets of readings of one series of films are available, and the films have been classified only according to the four I.L.O. categories, the possibilities of agreement and disagreement are as shown in
Fig. 2a: agreements fall in the hatched lattice; any case falling outside this lattice must be taken as a disagreement, by at least a complete category. Fig. $2 b$ illustrates the situation when using the experimental classification. Complete agreement (reproducibility) would require entries falling within the stippled lattice on this diagram; the area of potential complete agreement is seen to be considerably reduced. However, the extent of the disagreement indicated by falling outside this lattice may be considerably less than the complete category as when the conventional classification has been adopted. If, however, the same criterion of disagreement is adopted when using the experimental classification,

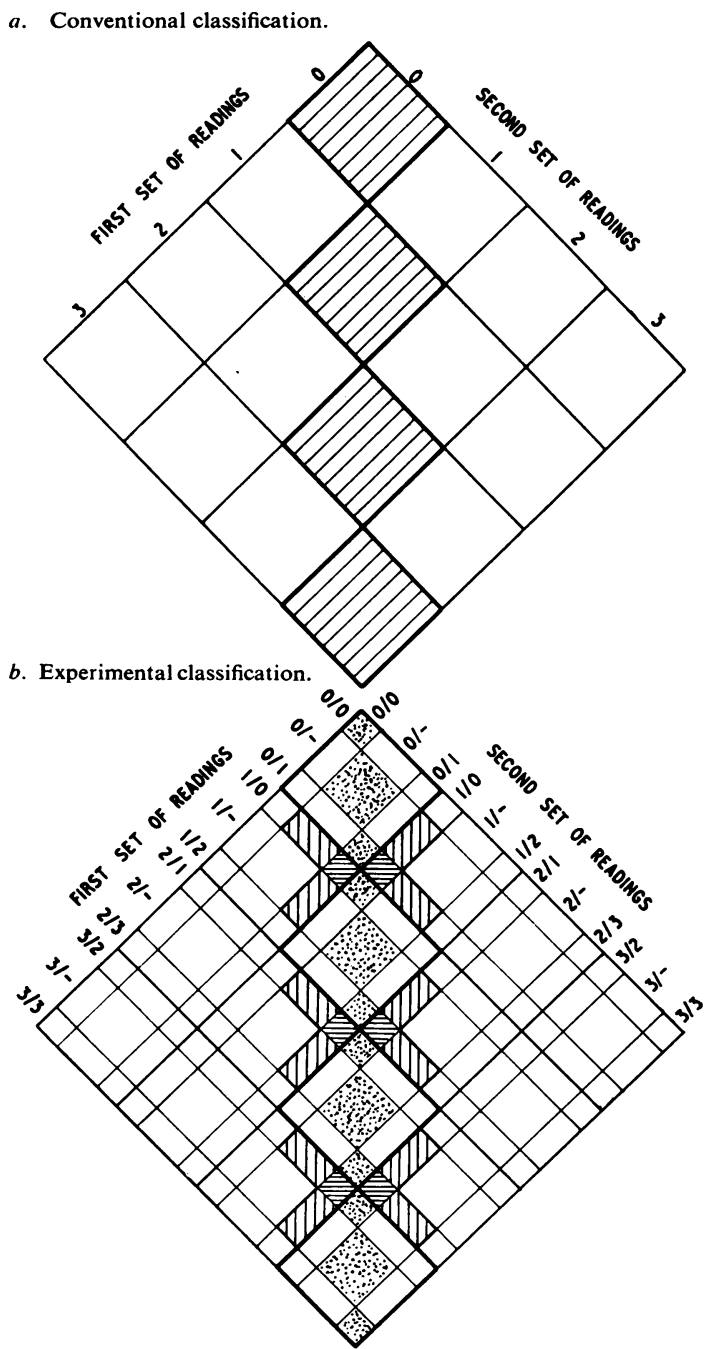

Fig. 2.-Areas of potential agreement. For explanation of symbols see text. 
the area of potential agreement is considerably expanded, i.e. to include the hatched areas of Fig. $2 b$. The areas with horizontal hatching are clearly those where disagreement is slight; reader $X$, say, states that the film is in one category with the adjacent category a real alternative, while reader $Y$ places the film in X's alternate, quoting X's first choice as his own alternate. In other words, both readers consider the film fairly close to the borderline between the two categories. An example would be readings of $1 / 2$ and $2 / 1$, which may be thought of as "high 1" and "low 2 ". The extent of disagreement when the readings fall within the areas hatched vertically can perhaps be explained best by means of an example and by reference to Fig. 1. Consider readings of $2 /-$ and $3 / 2$. With the reading $2 /-$, the implication is that the reader considers the radiological appearances sufficiently different from those of category 1 that he does not record $2 / 1$. The reading of $3 / 2$ means that the film is considered close to the boundary between categories 2 and 3 . The difference between the two readings is therefore at most from the lower edge of the central zone of category 2 (i.e. the lowest assessment of pneumoconiosis corresponding to 2/-) to the lower edge of the central zone of category 3 (i.e. the highest assessment of pneumoconiosis corresponding to $3 / 2$ ) and is therefore no more than a complete (I.L.O.) category.

\section{Intra-observer Error}

In this section we assess the practical effects of the experimental classification on intra-observer error but first examine the assumption upon which this experiment was carried out, i.e. that the "formal" category (that is the category recorded as that into which the film would have been classified conventionally) would be unaffected by the experimental method of reading. If this is so, intra-observer error would arise to a similar extent with both methods. This series of films had not formerly been read conventionally by the same readers independently and so comparison is made here with intraobserver error recorded in an earlier trial on a comparable series of films: 138 films of good quality (on average) showing a similar distribution of pneumoconiosis, which had been produced by sets $\mathrm{X} 1$ and $\mathrm{X} 2$ in a trial to compare $x$-ray sets (Liddell, 1961). The comparison is made in Fig. 3: in the upper part we give the two-way distributions showing intra-observer error on conventional reading of the series of 138 films by readers $A$ and $B$; in the lower part we give the corresponding distributions using the "formal" categories recorded in the current experiment by readers $A, B$, and $C$. For reader $A$, intra-observer error is seen to have been a little less on the experimental reading than on the conventional a. Conventional reading of 138 films.

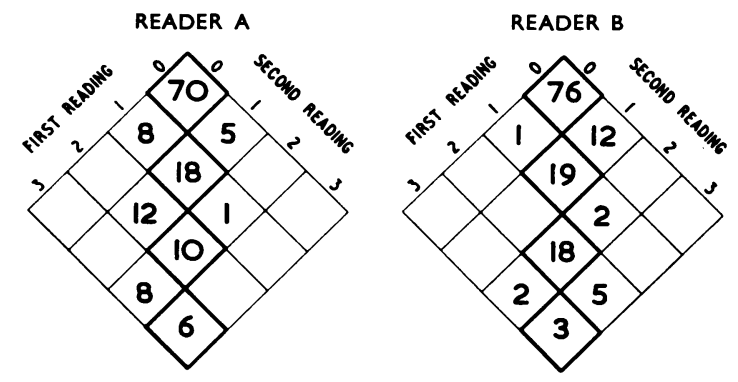

b. Experimental reading of 120 films (using "formal" categories).

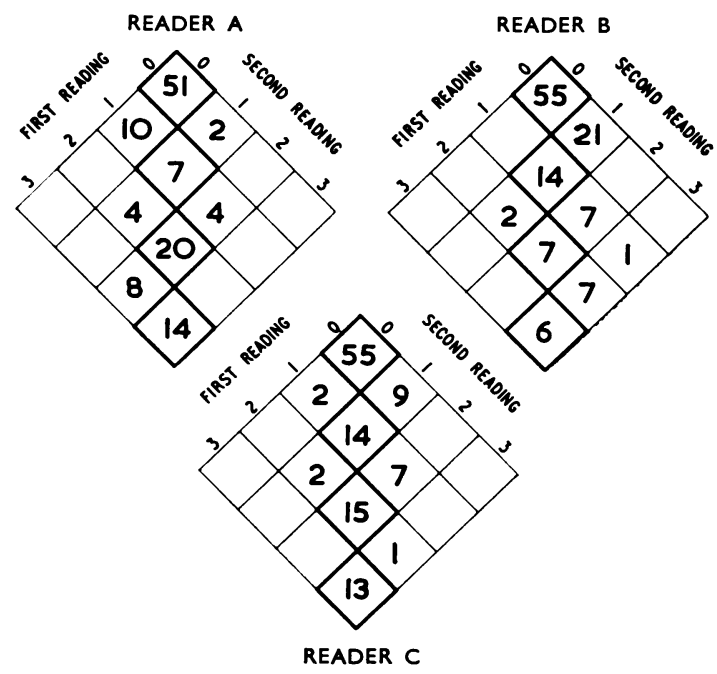

FIG. 3.-Intra-observer error in conventional and experimental reading.

reading, whereas for reader $B$ the reverse is true. As both these readers found the experimental method acceptable and, indeed, adopted it for their further reading, and as reader $C$ had the least intra-observer error in this experiment, it is considered that the assumption is very largely justified. It has been accepted in what follows*.

Fig. 4 illustrates the effects of the method of reading on intra-observer error for reader $\mathrm{A}$, i.e. it compares his readings on the first and second occasions. Fig. $4 a$ shows the two-way distribution of readings, extending the information given in Fig. 3, by taking account of the finer classification within the I.L.O. categories. As can be seen from the earlier figure, of the 120 pairs of readings by reader A, 92 fell within the zone of agreement; Fig. $4 a$ now shows that there is a general tendency for these 92 readings to lie close to the central vertical and not to

\footnotetext{
*This assumption is being examined directly in a more comprehensive experiment which is in hand at the time of writing: preliminary results indicate that it is, in fact, fully justified.
} 


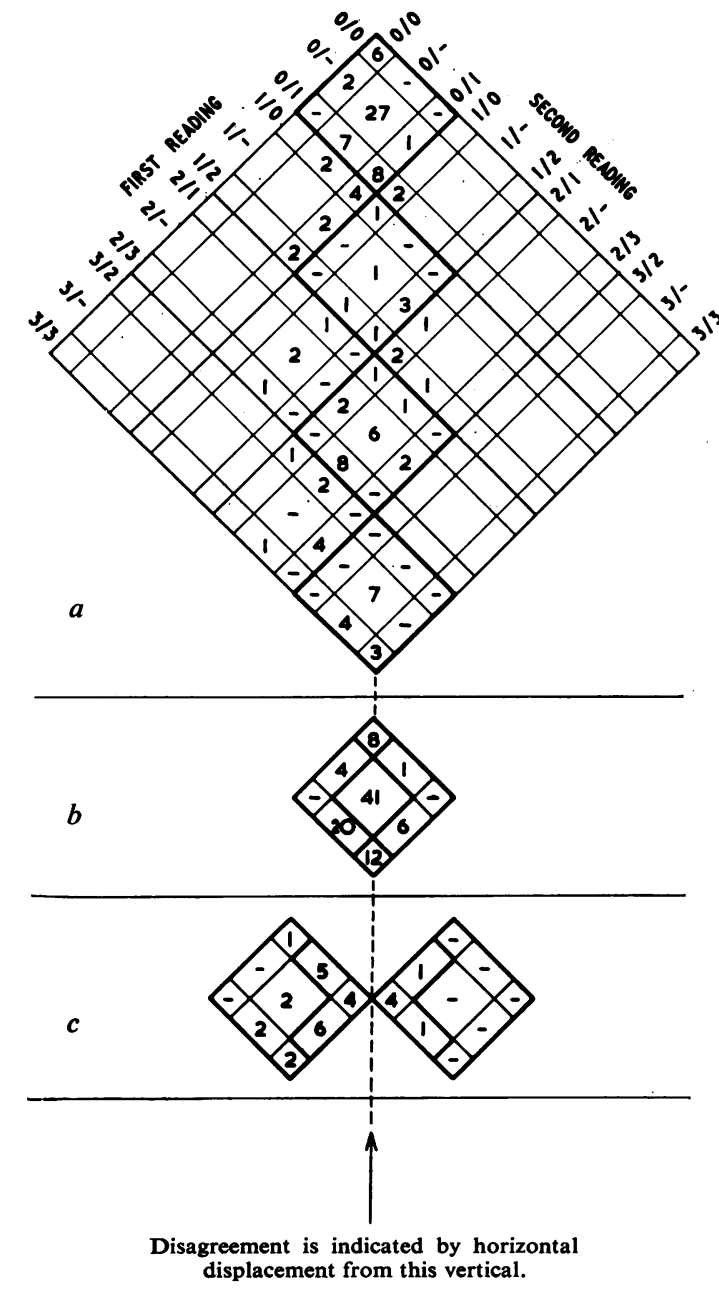

Fig. 4.-Intra-observer error: Reader A. $a$, Complete two-way distribution. $b$, Distribution in 92 cases where there was agreement over "formal" category. c, Distribution in 28 cases where there was disagreement over "formal" category.

be displaced to the extremes of the squares forming the central lattice. Information from this central lattice is summarized in Fig. $4 b$, where it can be seen that 61 of the 92 agreements in "formal" categories were also in perfect agreement even with the finer classification. The remaining 31 indicated only the most minor disagreement. There were no cases where reader $\mathbf{A}$ placed a film in the same I.L.O. category on the two occasions stating on the one that it was close to one boundary and on the other occasion that it was close to the other boundary; this is shown in Fig. $4 b$ by the blanks in the extreme left-hand and right-hand points of the diamond.

Of the 28 disagreements, seen in Fig. 3, which would have been counted a complete category "wrong" using conventional methods, all but seven lie in the area bounded by the bold lines in Fig. $4 c$, indicating agreement to within one I.L.O. category; eight of the disagreements are the least that can be recorded, and in a further 13 cases there was agreement within one category, as explained in Section 3 above.

Fig. 5 deals, similarly, with the readings by observers B and C. As can be seen from Fig. 5a, there is a considerable tendency, for these readers also, towards reproducibility even within the "formal" category, although it is not as clear as for reader A. Fig. $5 b$ deals with the disagreements over "formal" categories. For reader B, there were 38 (as can be seen from Fig. 3), and of these 28 fell within the area bounded by bold lines, indicating agreement within one category. The one disagreement by as much as two "formal" categories was on a film read $1 / 2$ on the first occasion and $3 / 2$ on the second; reference to Fig. 1 shows that this is disagreement by no more than a category and a half. For reader $\mathrm{C}$, Fig. $5 b$ shows a similar tendency towards agreement within one I.L.O. category, even where there was disagreement on "formal" categories.

Thus it seems clear that, at least for these three readers, the degree of intra-observer error is markedly

a. Distribution in cases where there was agreement over "formal" category.

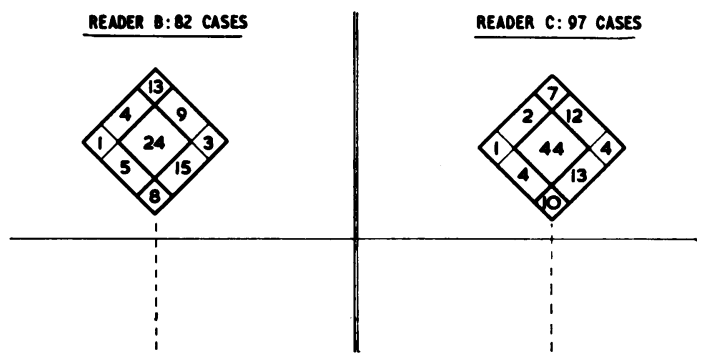

b. Distribution in cases where there was disagreement over "formal" category.

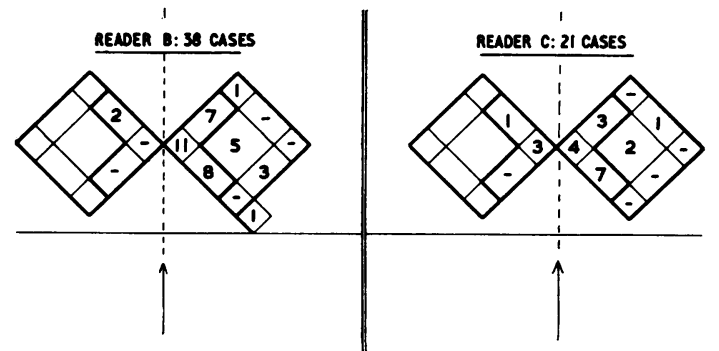

Disagreement is indicated by horizontal displacement from this vertical

Disagreement is indicated by horizontal displacement from this vertical.

FIG. 5.-Intra-observer error: Readers B and C. 
TABLE 3

ASSESSMENT OF INTRA-OBSERVER ERROR: FIRST READINGS COMPARED WITH SECOND READINGS

\begin{tabular}{r|c|c|c}
\hline & \multicolumn{2}{|c|}{$\begin{array}{c}\text { Average Amount of Information } \\
\text { (binary digits) }\end{array}$} \\
\cline { 2 - 4 } & $\begin{array}{c}\text { Reader } \\
\text { A }\end{array}$ & $\begin{array}{c}\text { Reader } \\
\text { B }\end{array}$ & $\begin{array}{c}\text { Reader } \\
\text { Cxperimental classification }\end{array}$ \\
\hline 120 Films in current trial & 1.90 & 1.48 & 1.64 \\
Conventional classification & 1.05 & 0.83 & 1.11 \\
\hline 138 Films in earlier trial \\
Conventional classification & 0.90 & 0.98 & - \\
\hline
\end{tabular}

improved by the experimental method of reading. Assessments can also be made quantitatively in terms of the average amount of information* transmitted, and Table 3 compares the errors arising in experimental and conventional reading, also comparing intra-observer error in conventional reading of the current films and of those from the previous trial (see the first paragraph of this section). The main conclusion of this section, that the experimental reading method leads to improved intraobserver error (more information), is clearly confirmed from this table, which also lends support to the acceptance of the assumption that the experimental method does not upset reading in "formal" categories.

\section{Inter-observer Error}

In this section we deal first with the results of the joint reading session and the establishment for each film of a "reference" reading against which to compare the performance of individual readers. Secondly, we compare inter-observer error when using the two reading methods.

The joint reading session was held some weeks after each reader had completed his two sets of individual readings. Each film was put up on a viewing box and each reader first recorded, unknown to the others taking part, his own reading, in the experimental classification. These readings were then announced, and an attempt was made to obtain an agreed reading, first in "formal" categories and then in the finer classification. For most of the films after the first 30, a record was made of the time taken between the film first being displayed and agreement being reached.

Table 4 indicates the amount of agreement or otherwise, together with the time taken to reach agreement. In 101 cases agreement was eventually reached, even in the finer classification, and this within a fairly short time, although the average time

*In the sense of Shannon (1948); this can be considered here simply as a statistic which acts as an inverse measure of error (see Appendix). taken to reach agreement increased with the degree of initial disagreement. In the remaining 19 cases, full agreement could not be reached and the time taken to come to the conclusion that this was so was always considerable. It is possible that in these cases there was disagreement of a qualitative nature, and

TABLE 4

RESULTS OF JOINT READING SESSION

\begin{tabular}{|c|c|c|c|}
\hline & \multirow{2}{*}{$\begin{array}{l}\text { No. of } \\
\text { Films }\end{array}$} & \multicolumn{2}{|c|}{$\begin{array}{l}\text { Time to reach } \\
\text { Agreement (sec.) }\end{array}$} \\
\hline & & Average & Range \\
\hline \multirow[t]{2}{*}{$\begin{array}{l}\text { Agreement reached } \\
\text { after the independent readings had: } \\
\text { agreed exactly } \\
\text { disagreed marginally } \\
\text { agreed within one category } \\
\text { disagreed by more than one } \\
\text { category }\end{array}$} & $\begin{array}{r}34 \\
32 \\
27 \\
8\end{array}$ & $\begin{array}{r}30 \\
87 \\
127 \\
123\end{array}$ & $\begin{array}{l}(1-61) \\
(15-171) \\
(67-240) \\
(70-163)\end{array}$ \\
\hline & $\begin{array}{r}101 \\
19\end{array}$ & $186^{*}$ & $(131-325)$ \\
\hline Total & 120 & & \\
\hline
\end{tabular}

*Time taken to conclude agreement was not possible

the writer's impression, from listening to the discussion which, unfortunately, was not recorded, bears this out.

Where an agreed reading was obtained it can be used as reference against which inter-observer error can be assessed. In Table 5, the average amount of information is quoted for all three readers when using the experimental and the conventional method of reading both during the joint reading session and in their own second sessions. It is clear that, in every case, more information was obtained, i.e. observer

TABLE 5

ASSESSMENT OF INTER-OBSERVER ERROR: USING AGREED READING (FROM JOINT SESSION) AS REFERENCE

\begin{tabular}{|c|c|c|c|c|}
\hline & & \multicolumn{3}{|c|}{$\begin{array}{c}\text { Average Amount of } \\
\text { Information (binary digits) }\end{array}$} \\
\hline & & $\underset{\mathbf{A}}{\text { Reader }}$ & $\underset{\text { B }}{\text { Reader }}$ & $\begin{array}{c}\text { Reader } \\
\text { C }\end{array}$ \\
\hline$\overline{(a)}$ & $\begin{array}{l}\text { Third "independent" readings } \\
\text { Experimental classification } \\
\text { Conventional classification }\end{array}$ & $\begin{array}{l}2.00 \\
1.33\end{array}$ & $\begin{array}{l}1.85 \\
1.15\end{array}$ & $\begin{array}{l}2 \cdot 34 \\
1.42\end{array}$ \\
\hline & $\begin{array}{l}\text { Second independent readings } \\
\text { Experimental classification } \\
\text { Conventional classification }\end{array}$ & $\begin{array}{l}1.83 \\
1.11\end{array}$ & $\begin{array}{l}1.56 \\
0.97\end{array}$ & $\begin{array}{l}1.44 \\
1.02\end{array}$ \\
\hline
\end{tabular}

error was less, when the experimental classification was used.

However, this analysis has two serious drawbacks. First, only the films over which complete agreement was obtained could be dealt with, and, secondly, it may be considered suspect to use results from the joint reading session since there may have been a tendency for the readers to adjust their reading levels during 
the session so as to bring them more into line with each other's than might have been normal. In the following paragraphs we consider a way of getting over these difficulties.

For each of the 101 films where agreement was reached, the median of the three independent readings during the joint session was found: where all three observers recorded the same reading, this is the median; when two agreed and the third differed, the median is the reading of the two agreeing; when all three differed, the median is the central of the three readings. In 81 of the 101 cases, the agreed reading was also the median, and for all but two of the other 20 films the median reading differed only marginally from the agreed reading; the two outstanding cases were of median $1 /$ - compared with agreed $0 / 1$, and median $3 /$ - compared with agreed $2 / 3$. Half of the 20 differences were in one direction, half in the other. In view of this close resemblance of the median reading to the agreed reading and since the median reading is, of course, determinate even in cases where agreement as such cannot be reached in a joint session, it can be used with some confidence as a reference against which observer error can be assessed.

We can overcome the second difficulty by using solely the material from one set of truly independent reading sessions. The readings obtained at the second session for each observer were used for this purpose on the grounds that in the first sessions the readings may have been affected to some extent by the fact that this was the first time such methods had been attempted. Fig. 6 illustrates the performance of reader $A$ assessed in this way, while Table 6 is a summary of the results of this analysis for all readers; they again show that markedly more inform-

TABLE 6

ASSESSMENT ON INTER-OBSERVER ERROR: SECOND READINGS REFERRED TO MEDIAN OF SECOND READINGS

\begin{tabular}{l|c|c|c}
\hline & \multicolumn{2}{|c}{$\begin{array}{c}\text { Average Amount of } \\
\text { Information (binary digits) }\end{array}$} \\
\cline { 2 - 4 } & $\begin{array}{c}\text { Reader } \\
\text { A }\end{array}$ & $\begin{array}{c}\text { Reader } \\
\text { B }\end{array}$ & $\begin{array}{c}\text { Reader } \\
\text { C }\end{array}$ \\
\hline Experimental classification & 1.80 & 1.86 & 2.03 \\
Conventional classification & 1.05 & 1.11 & 1.41 \\
\hline
\end{tabular}

ation is obtained when using the experimental classification than by the conventional method. This finding has been repeated in each of a whole series of studies of inter-observer error which have been carried out, i.e. comparing the independent readings at various sessions with a number of different reference readings. a. Experimental classification.

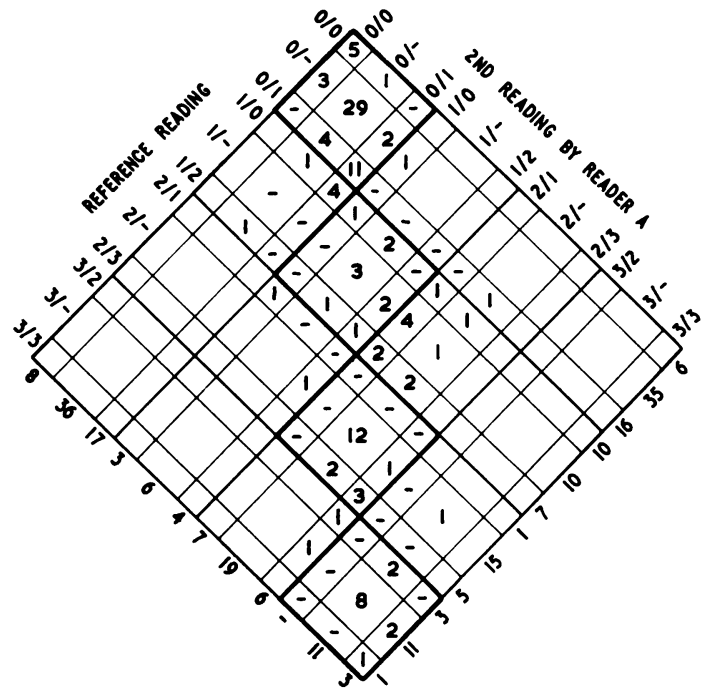

b. Using "formal" categories only.

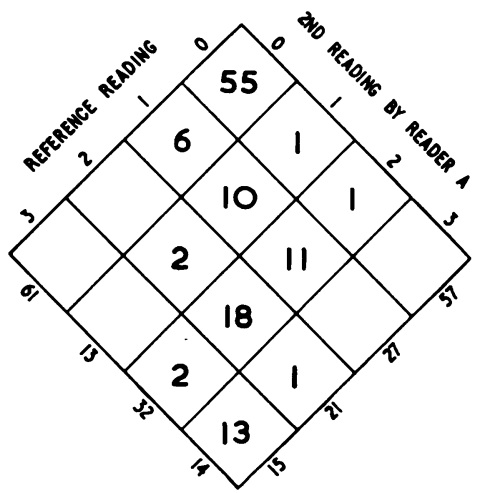

FIG. 6.-Inter-observer error: Reader A. Readings on second occasion referred to median of second readings.

Another method of examining inter-observer error is illustrated in Fig. 7, where the second sets of readings by observers $A$ and $B$ are presented. In Fig. 7a, the readings are given in terms of "formal" categories. Then, the lower portions summarize the information obtained in the experimental classification; Fig. $7 b$ shows the amount of agreement in the finer classification, where there was agreement in terms of "formal" categories; Fig. $7 c$ shows the extent of the disagreement between the pair of readers when the readings differed by one "formal" category; and Fig. $7 d$ deals with disagreements by two "formal" categories.

Fig. $7 b$ shows that this pair of readers agreed to a considerable extent even on the finer classification. Of 78 cases of agreement to within a "formal" 


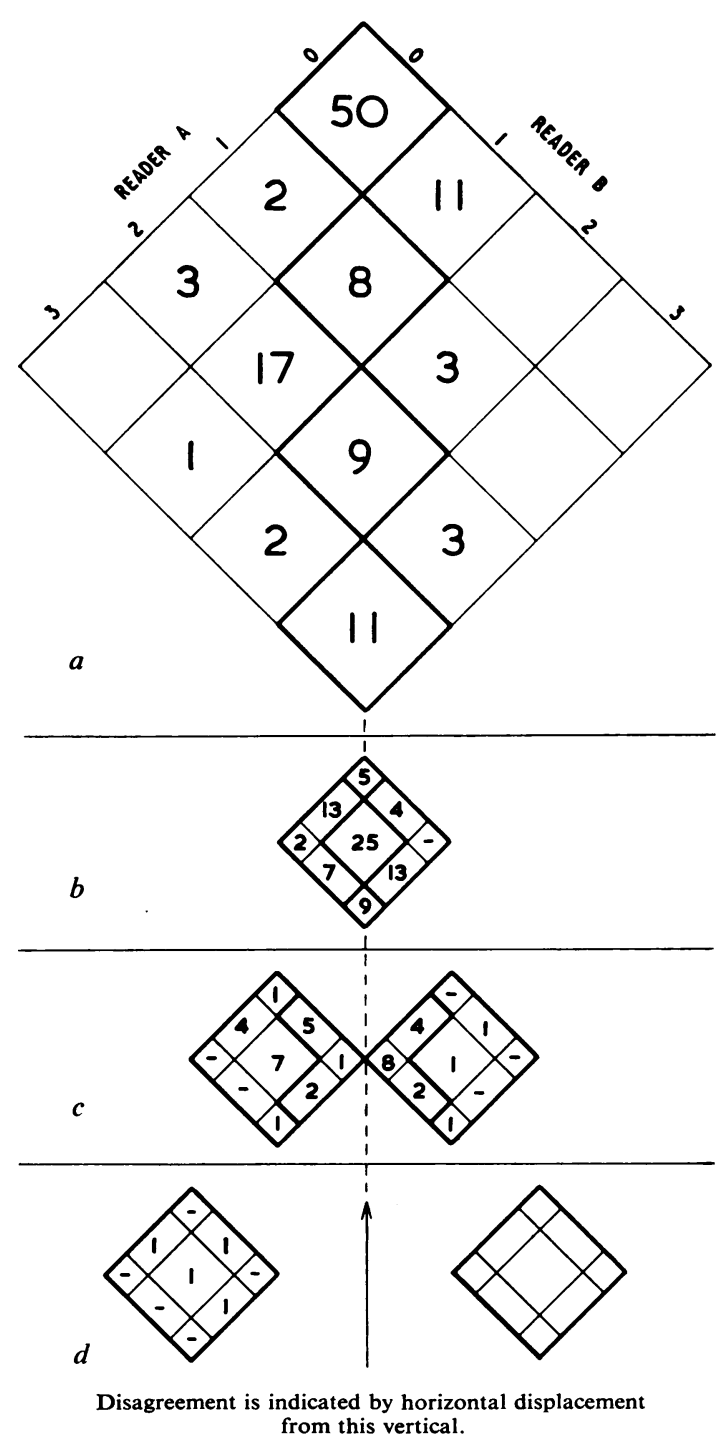

Fig. 7.-Inter-observer error: Readers $\mathbf{A}$ and B. $a$, Two-way distribution of "formal" categories. $b$, Distribution in 78 cases where there was agreement over "formal" category. c, Distribution in 38 cases where there was disagreement by one "formal" category. $d$, Distribution in four cases where there was disagreement by two "formal" categories.

category, just half (39) were also agreed exactly in the finer classification. The vast majority of the remainder (37) showed minimal disagreement, and in only two cases did one reader quote as alternate one adjacent category and another reader quote the other. Fig. $7 c$ shows that of 38 disagreements by one "formal" category the disagreement was minimal in nine cases and in a further 13 cases was within the areas bounded by bold lines, indicating agreement within one category. There were only four disagreements by two "formal" categories, and two of these were of less than two categories when the finer classification was taken into account.

Comparisons on the same basis between readers $A$ and $C$ and between readers $B$ and $C$, together with comparisons based on the readings obtained in the first sessions and on those by one reader in his first session with those of another reader in his second session and vice versa, numbered 1,312. Agreement in terms of "formal" categories was observed in 895 cases: of these, 488 also showed exact agreement on the refined classification; 364 showed minimal disagreement, leaving 43 showing disagreement from the bottom of a (I.L.O.) category to the top. Disagreements by one "formal" category numbered 356: of these, 57 were minimal disagreements, and in a further 117 cases the disagreement was by no more than a category when account was taken of the finer classification. Again of 57 disagreements by two "formal" categories, 41 appeared less on the finer classification, while all four disagreements by three "formal" categories similarly appeared less. Summarizing the material above and from Fig. 7, the experimental classification led to agreement within a (I.L.O.) category in $82 \%$ of cases, compared with only $68 \%$ in terms of "formal" categories, and to disagreement by more than two (I.L.O.) categories in only $1 \frac{1}{2} \%$ of cases, compared with $4 \frac{1}{2} \%$ in terms of "formal" categories.

Thus, the various methods of assessment all suggest strongly that inter-observer error also is considerably reduced by the experimental classification.

\section{Effects on the Assessment of the Progression of Pneumoconiosis}

An assessment of the progression of pneumoconiosis among the 40 subjects between 1949 and 1956 can be made in terms of any one observer's independent readings of the 80 films (read in random order; not side by side). As the patterns for the three observers are closely similar, the results have been combined in one diagram (Fig. 8). (It should be emphasized that the 120 entries here are those of the three readers on 40 pairs of films and do not, as in previous diagrams, relate to 120 films assessed by one reader twice or by two readers.) Fig. $8 a$ shows the pairs of readings of the 1949 and 1956 films based on "formal" categories. In a form analogous to that used in the preceding diagrams, the lower parts indicate the finer categorization: Fig. $8 b$ deals with the apparent retrogression in "formal" categories; Fig. $8 c$ with cases of no change in "formal" category; and Fig. $8 d$ with progression in "formal" categories. 

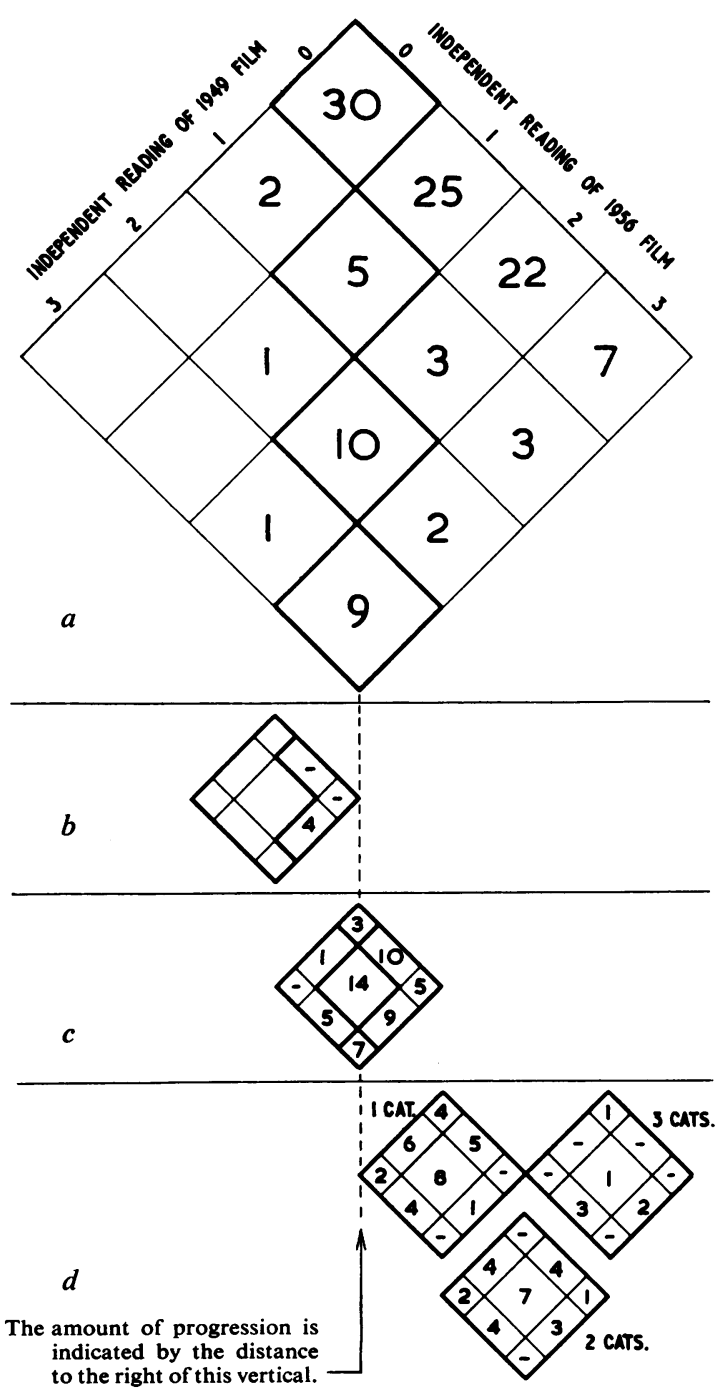

Fig. 8.-Progression, 1949 to 1956: All readers. $a$, In "formal" categories. b, Apparent retrogression in "formal" categories. $c$, No change in "formal" category. $d$, Progression in "formal" categories.

From Fig. $8 b$ it can be seen that, in all four cases of retrogression assessed in terms of "formal" category (one by reader $\mathrm{A}$, one by $\mathrm{B}$, and two by $\mathrm{C}$ ), the degree of retrogression was less than that of a complete category when account is taken of the more refined reading.

Fig. $8 c$ shows that on average a considerable degree of progression was assessed in terms of the experimental classification even in those cases where the "formal" category was the same for a subject's films in the two years. The results for the individual readers are as follows:

\begin{tabular}{c|c|c|c|c|c}
\hline \multirow{2}{*}{ Reader } & \multicolumn{2}{|c|}{ Retrogression } & $\begin{array}{c}\text { No } \\
\text { Change }\end{array}$ & \multicolumn{2}{c}{ Progression } \\
\cline { 2 - 5 } & Max.* & Min. $\dagger$ & & Min. $\dagger$ & Max.* \\
\hline A & - & 2 & 7 & 9 & 1 \\
B & - & 3 & 7 & 5 & 3 \\
C & - & 1 & 10 & 5 & 1 \\
\hline All readers & - & 6 & 24 & 19 & 5 \\
\hline
\end{tabular}

* From one end of a (I.L.O.) category to the other (e.g. from $2 / 3$ to $2 / 1$ or from $1 / 0$ to $1 / 2$ )

tThe minimum that could be recorded (e.g. from $1 / 2$ to $1 /-$ or from $2 /-$ to $2 / 3$ )

In other words, the six cases of minimal retrogression only partially balance the 19 of minimal progression, while there was evidence of greater progression in a further five cases.

On the other hand, from Fig. $8 d$ it can be seen that there was a slight tendency for the experimental method of reading to indicate progression by less than complete categories where the use of "formal" categories indicated progression. This tendency balances to some extent the opposite tendencies discussed in the preceding paragraphs. However, from these films, the overall impression is that the amount of progression is understated by using conventional methods of independent reading.

Comparisons have also been made of readings on the 1949 and 1952 films and of readings on the 1952 and 1956 films. The same general tendencies were found. The apparent retrogressions in "formal" categories (13 of them) tended to be marginal (4 cases) or by less than a category (a further 6 cases) with the remaining (3) cases indicating just one category retrogression. There were 128 pairs of films placed in the same "formal" category: minimal progression was recorded in 40 of these pairs, partly balanced by minimal retrogression in only 16 ; progression from the bottom of one category to the top of it was recorded in seven pairs, compared with one retrogression of similar degree. In cases where "formal" categories indicated progression, the finer classification indicated a lesser degree of progression on average, the effect being rather more marked than in the corresponding seven-year comparisons. The overall impression is of a slight understatement of progression when using the conventional classifcation in an independent reading of these films also.

Whether or not progression is diagnosed in any particular subject also depends on the classification used. This can be examined in terms of a hypothetical example: for a subject whose films taken in 1949 and 1956 had reference readings (the median of 
TABLE 7

CONFIDENCE IN THE DIAGNOSIS OF PROGRESSION

Probabilities of readings* of two films for one subject, with reference readings:Earlier film - Category 1
Later film - Category 2

\begin{tabular}{|c|c|c|c|c|}
\hline \multirow{2}{*}{\multicolumn{2}{|c|}{ Reading* of Earlier Film, with Probabilities in brackets }} & \multicolumn{3}{|c|}{ Reading* of Later Film, with Probabilities in brackets } \\
\hline & & \multirow{2}{*}{$\begin{array}{c}\frac{\text { Category 1 }}{(2 \text { chances in 21) }} \\
2 \cdot 1 \% \dagger\end{array}$} & \multirow{2}{*}{$\begin{array}{c}\begin{array}{c}\text { Category } 2 \\
\text { chances in 21) }\end{array} \\
19.0 \%\end{array}$} & \multirow{2}{*}{$\frac{\begin{array}{c}\text { Category } 3 \\
\text { (1 chance in 21) }\end{array}}{1 \cdot 1 \%}$} \\
\hline Category 0 & (6 chances in 27) & & & \\
\hline Category 1 & ( 10 chances in 27$)$ & $3.5 \%$ & $31 \cdot 7 \%$ & $1.8 \%$ \\
\hline Category 2 & ( 11 chances in 27 ) & $3.9 \%$ & $34.9 \%$ & $1.9 \%$ \\
\hline
\end{tabular}

* By reader $\mathbf{A}$ on his second session

+ Found as $100 \times(6 / 27) \times(2 / 21)$

the independent readings on second sessions) of (I.L.O.) categories 1 and 2 respectively, would an observer diagnose progression in independent reading? Consider reader $A$ on his second session; from Fig. $6 b$ the probabilities of his reading of the 1949 film can be estimated as six chances in 27 of reading category $0 ; 10$ in 27 of reading category 1 ; and 11 in 27 of reading category 2 . Corresponding probabilities can be obtained for his reading of the 1956 film so that the probabilities of various combinations of readings of the two films are as in Table 7 . The probability of this reader diagnosing progression, therefore, is the sum of the probabilities in this table in which the 1956 film is read as in a higher category than the earlier film, i.e. as the sum of the entries above the stepped line, and is found as $58 \%$. If the experimental classification had been used and the hypothetical subject had had films with reference readings $1 / 0$ and $1 / 2$, the corresponding probability of reading progression can be worked out, similarly, as $69 \%$. In other words, when using the experimental classification, reader $\mathbf{A}$ would have had a slightly greater chance of diagnosing progression, where the two films for a subject differed in reference reading only from the bottom to the top of a (I.L.O.) category, than he would have had when using the conventional classification where the reference readings differed by a complete (I.L.O.) category.

A series of calculations on similar lines, for different readers and for progression along different parts of the continuum of abnormality, confirmed that diagnosis of progression would have been more likely when using the experimental classification than when using the conventional classification in every case in which the reference readings indicated progression.

\section{Discussion}

In case it should be felt that the results reported here would apply only to highly skilled readers, the writer's own readings were compared with those of Dr. Chapman, who was his mentor. They showed that, although the element of observer error was the greatest shown, the same general tendencies appeared. Similarly, when the writer's assessments of films from different years of the same subject were compared (as in Section 6 above) the same trends appeared although they were all less marked than for the skilled readers. To obtain further evidence, an experiment on a considerably larger scale is in hand at the time of writing, and the preliminary results are similarly encouraging.

The evidence presented suggests that the degree of error, both intra-observer and inter-observer, can be considerably reduced by use of the experimental classiflcation. This bears out the theoretical considerations of Section 3 and was considered a justification for the more extensive trial now in hand.

Some doubts have, however, been expressed about the effects that may arise because of variation in the quality of the films. A reader may tend to consider alternative categories more frequently in cases of poor films than with good films. The films used in this experiment are reported to have been of good quality on average. Those in the trial currently in hand are of a more mixed quality, but here the proportion of films in which there has been equivocation, i.e. those in the marginal zones, has remained fairly comparable with that reported here. Nevertheless, this aspect is being examined more closely.

Further doubts have been expressed about the use of the classes $0 / 0$ and $3 / 3$ and that the definitions of the various categories are nebulous. On the other hand, there is a considerable body of opinion that the "barn-door" normals can be distinguished from "category $\frac{1}{2}$ " films. It is important to be sure that the distinction between a $0 / 0$ and a $0 /-$ film is in fact due to early development of pneumoconiosis and not to changes in appearance due to ageing, film quality or radiation scatter. At the other end of the 
continuum, the class $3 / 3$ may be permissible in that changes due to simple pneumoconiosis could keep on increasing indefinitely. Several of the Board's film readers have commented that they prefer to use the experimental classification, but it must be borne in mind that this may be (subconsciously) because it gives them the opportunity for equivocation. It is certainly clear that the classification is still only experimental and that, in any case, the justification of any classification can only be, in the final analysis, in terms of the extent to which it relates to lung pathology. Some attempts have been made to correlate radiographic appearances, defined conventionally, with lung pathology or dust in the lung (see, for example, Rivers, Wise, King, and Nagelschmidt, 1960; Caplan, 1962). A more radical approach would be to classify lungs according to pathology (or dust) and examine the radiographs in order to discover, if at all possible, the factors which are common within classes and the differences between these common factors from one class to another. A classification based on the factors so determined might differ considerably from the classification at present in use and, if so, would appear to be more soundly based.

The desire to attain greater sensitivity (more information) is itself only a means to the main aim of assessing progression. Other methods of attaining sensitivity can be used when multiple reading is possible, and this seems, intuitively, preferable to the use of joint reading into a small number of "definitive" categories.

As to the assessment of progression itself, no firm conclusions can be drawn from the results of Section 6 because the apparent understatement of progression, when using the conventional classification, appears to depend on the degree of progression. With present mining practice in this country, it seems likely that rather less progression can be expected, and it may well be that, over a five-year interval (as adopted for the Board's Periodic $X$-ray Scheme), the great majority of pairs of films for individual subjects would be placed in the same "formal" category, were the conventional classification to be used. Thus a considerable degree of true, though minor, progression may perhaps be concealed by "independent" reading into "formal" categories. This has been considered a (statistically) unbiassed method of measuring progression but may possibly not in fact be so. On the other hand, although "side-by-side" reading has been criticized on the grounds that it introduces biasses when compared with "independent" reading, this criticism would appear to require further consideration in the light of the findings reported here. It seems likely that "side-by-side" reading will be adopted for clinical purposes in the Periodic $X$-ray Scheme and this method may conceivably be found, in the end, to be the most appropriate for assessing progression, particularly should it prove possible to define and validate a direct measure of progression.

I wish to thank Dr. Gilson, Dr. Miall, and Dr. Chapman for their whole-hearted co-operation in this experiment. They and many others also helped greatly in much useful discussion and criticism. However, the views expressed are my own and must not be taken to commit the National Coal Board or any others in any way.

\section{REFERENCES}

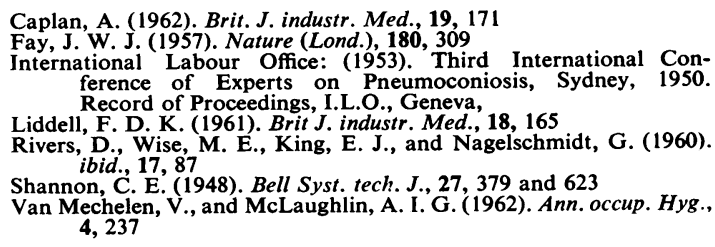
ference of Experts on Pneumoconiosis, Sydney, 1950. Record of Proceedings, I.L.O., Geneva,

Liddell, F. D. K. (1961). Brit J. industr. Med., 18, 165

Rivers, D., Wise, M. E., King, E. J., and Nagelschmidt, G. (1960). ibid., 17, 87

Shannon, C. E. (1948), Bell Syst. tech. J., 27, 379 and 623

Van Mechelen, V., and McLaughlin, A. I. G. (1962). Ann. occup. Hyg., 4, 237

\section{Appendix}

The statistic of average amount of information transmitted has its place in a theory (Shannon, 1948) which was developed for use in communications, but here it is used simply as an inverse measure of observer error; the greater the information transmitted the lower the observer error. In this Appendix, we discuss briefly the computation of this statistic (by means of an example), its properties, and its validation as an indicator of error.

The example chosen for illustrating the calculation is the assessment of inter-observer error in the case of reader $A$ in the current trial, comparing his second set of independent readings against the median reading from the three readers' second sessions, used as reference. The data are in Fig. 6: for the sake of simplicity we consider the case where only "formal" categories are used, but the method of calculation can be used for all the problems of observer error discussed in this paper. The method presented here has been simplified so that the whole process of calculation takes only two or three minutes even for the $12 \times 12$ tables involved with the experimental classification.

The computation consists almost entirely of the addition of terms of the form $n\left(\log _{2} n\right)$; values of these terms for $n$ up to 120 are given in Table 8 . The steps in the computation are as follows:

1. Add together the values of $n\left(\log _{2} n\right)$ corresponding to each cell frequency to obtain: (a) $=318.0+15.5$ $+33 \cdot 2+2 \cdot 0+38 \cdot 1+75 \cdot 1+2 \cdot 0+48 \cdot 1=532 \cdot 0$

Note that, although there are 16 cells in the two-way table of Fig. 6 there are only eight terms in the first expression for $(a)$; this is because five of the 16 cells are blank and in three more the frequency is one, so that none of these contributes to $(a)$.

2. Find the numbers of films in each of the four categories according to the reference reading, i.e. 57, 27, 21 , and 15 , and add together the corresponding values of 
TABLE 8

VALUES OF $n\left(\log _{2} n\right)$

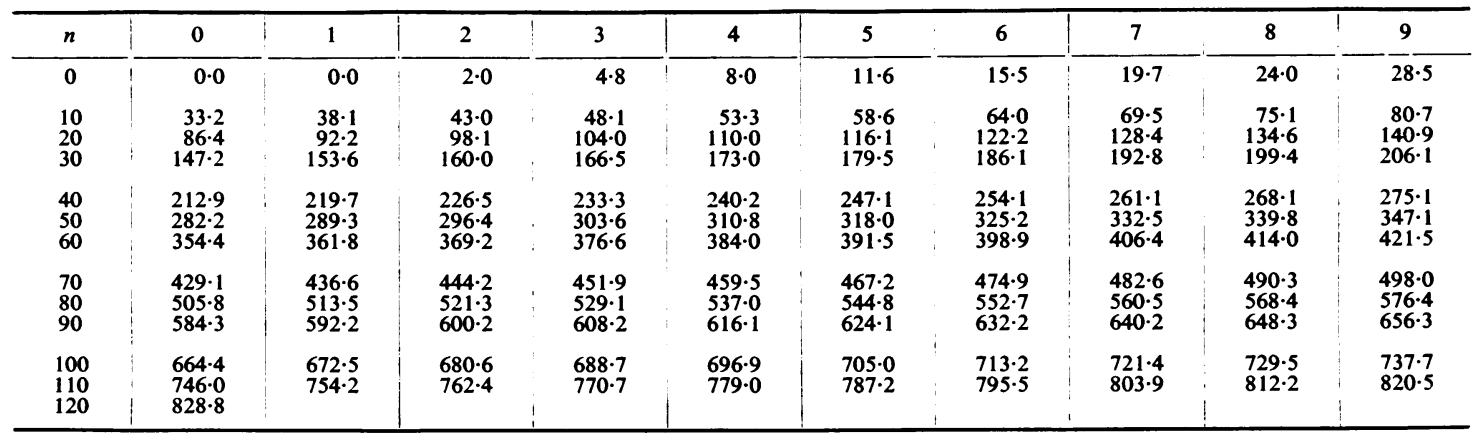

TABLE 9

AVERAGE TRANSMITTED INFORMATION AS A MEASURE OF OBSERVER ERROR: SECOND READINGS BY READER A REFERRED TO MEDIAN OF SECOND READINGS

\begin{tabular}{|c|c|c|c|c|c|c|c|}
\hline \multicolumn{3}{|c|}{ Classification for } & \multicolumn{5}{|c|}{ Average Amount of Information (binary digits) } \\
\hline & Reference Reading & Individual Reading & $\begin{array}{l}\text { Theoretical } \\
\text { Maximum } \\
\text { Information }\end{array}$ & $\underset{\substack{\text { Maximum } \\
\text { Information }}}{\text { Actual }}$ & $\begin{array}{c}\text { Information } \\
\text { Lost }\end{array}$ & 1 & $\begin{array}{l}\text { Information } \\
\text { Transmitted }\end{array}$ \\
\hline (1) & Conventional & Conventional & $2 \cdot 00$ & $1 \cdot 81$ & 0.76 & & $1 \cdot 05$ \\
\hline (2) & & $\begin{array}{c}\text { Conventiona! } \\
\text { ("perfect") }\end{array}$ & $3 \cdot 58$ & 3.09 & $1 \cdot 37$ & & $1 \cdot 71$ \\
\hline (4) & Experimental & Experimental & $3 \cdot 58$ & $3 \cdot 09$ & $1 \cdot 29$ & & $1 \cdot 80$ \\
\hline
\end{tabular}

$n\left(\log _{2} n\right)$, to obtain: $(b)=332 \cdot 5+128 \cdot 4+92 \cdot 2+58 \cdot 6$ $=611 \cdot 7$

3. Similarly, find the number of films in each of the four categories according to reader $\mathrm{A}$, i.e. $61,13,32$, and 14 , and add together the corresponding values of $n\left(\log _{2} n\right)$, to obtain: $(c)=361 \cdot 8+48 \cdot 1+160 \cdot 0+53 \cdot 3=623 \cdot 2$

4. Find the value of $N\left(\log _{2} N\right)$ where $N$ is the total number of films, in this case 120 . This gives $(d)=828.8$

5. Now calculate the required statistic as: $[(a)-(b)$ $-(c)+(d)] / N=(125.9) / 120=1.05$ binary digits

The upper limit to the value of this statistic depends simply on the number of categories adopted for the reference reading, and is $\log _{2}$ (number of categories); for the conventional classification (four categories) it is thus 2.00 binary digits and for the experimental classification (12 classes) it is 3.58 digits. However, in any practical application, the actual maximum depends on the distribution of the reference readings over the available categories. This measure can be obtained as a by-product of the calculation already outlined, as $[(d)-(b)] / N$ or in the example $(217 \cdot 1) / 120=1 \cdot 81$ binary digits. This maximum does not vary very much provided the distributions of the reference readings are not too dissimilar. For all the applications discussed in this paper it varies only by approximately $\pm \mathbf{0 . 2 0}$ for each classification. The maximum could only be obtained if, for every film, the reading by any particular observer is the same as the reference reading. In practice, there is, of course, a loss of information. The value of this loss can also be obtained as a by-product of the earlier calculation as $[(c)-(a)] / N$; in the specific case, it is 0.76 binary digits.

Table 9 details these various measures for each of a number of ways in which the data of Fig. 6 have been treated. Line (1) assumes the use of the conventional (I.L.O.) classification throughout, i.e. as in Fig. $6 b$. In lines (2) and (3) we take the reference reading in the experimental classification and consider what would happen to the measures of information if the individual reader adopted the conventional classification: in line (2) we assume he was "perfect" in always placing the film in the same I.L.O. category as indicated by the reference reading; and in line (3) we quote the figures for the actual use of the conventional classification for the individual readings compared with reference readings in the experimental classification. Finally, in line (4), we consider the use of the experimental classification throughout. It can be seen from line (1) of this table that the initial information is small and, although the loss is small also, the transmitted information is the smallest recorded. Line (2) shows that the use of the conventional classification must lead to a considerable loss of information in theory; while line (3) shows how much greater this loss becomes in practice. Line (4) shows that the transmitted information is greatest when the experimental classification is used throughout. Thus reader A actually obtained as much information by means of the experi- 
mental classification as he could possibly have obtained, even with perfect reading, in the conventional classification. Reference to Table 6 shows that this was true for the other two readers also. This is because of the tendencies, illustrated in Figs. 6 and 7, for the disagreements by "formal" categories to be less than complete (I.L.O.) categories and towards complete agreement even within the finer classification. Without these tendencies the information obtained would have been as in line (3). Thus, although there is a slight increase in the information transmitted because the experimental classification is used for the reference reading, by far the more important gain comes from the use of the experimental classification for individual reading.

The statistic we are discussing has the basic property that it is an inverse measure of observer error. In other words, the higher its value* the lower the error. Its lowest possible value is zero, which would arise if a reader had no ability to discriminate in reading and so placed films into categories at random showing no relation to the reference reading.

In the following paragraphs we make an heuristic validation of the use of transmitted information as an inverse measure of observer error. For this purpose, we use an arithmetic procedure which may appear simple and straightforward, but which has a major statistical drawback. This procedure is to introduce a "scale" of abnormality and to "measure" deviations between readings in terms of this scale, which is devised as follows. We let the mid-points of the four "formal" categories correspond to the points $0,1,2$, and 3 on the scale. We then take each central zone as of width $\frac{1}{2}$ and notice that therefore they stretch $\pm \frac{1}{4}$ on each side of the points already defined, while the marginal zones will stretch from, for example $\frac{1}{4}$ to $\frac{1}{2}$, with mid-point $\frac{3}{8}$. Thus, the scale for use with the experimental classification becomes:

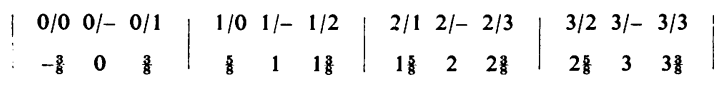

Now, for each reading compared with a reference reading we can "measure" the deviation in terms of this scale. For example, if the observer had read a film as $0 / 1$, whereas the reference reading was $1 /-$, the deviation would be taken as $-\frac{5}{8}$. We can then find, for any particular set of readings, the mean and the variances of these deviations. In the examples of Fig. 6 the distributions of deviations are as given in Table 10.

From these distributions we obtain the means and variances of the deviations, by the usual methods (Table 11).

The drawback of this procedure is that the use of the scale implies that equal distances along the scale have the same meaning at all points of the continuum of abnormal-

\footnotetext{
*It is the absolute value that has to be considered, not the value
} relative to the maximum or to the upper limit. ity. Thus, the difference between readings of $0 / 0$ and $0 /-$ is taken to mean exactly the same ( $\frac{8}{8}$ of a unit on the scale) as that between readings of, say, $1 /-$ and $1 / 2$ or between $3 / 2$ and $3 /-$, while differences between readings of, say,

\section{TABLE 10}

\begin{tabular}{|c|c|c|}
\hline \multirow{2}{*}{ Deviation } & \multicolumn{2}{|c|}{ Frequency of this Deviation } \\
\hline & $\begin{array}{l}\text { Experimental } \\
\text { Classification }\end{array}$ & $\begin{array}{l}\text { Conventional } \\
\text { Classification }\end{array}$ \\
\hline $\begin{array}{l}+2 \\
+18 \\
+18 \\
+18 \\
+8 \\
+\frac{8}{8} \\
+\quad \frac{1}{4} \\
0 \\
-4 \\
-\frac{3}{8} \\
-18 \\
-1 \\
-18\end{array}$ & $\begin{array}{r}- \\
1 \\
1 \\
3 \\
7 \\
12 \\
2 \\
74 \\
5 \\
10 \\
3 \\
1 \\
1\end{array}$ & $\begin{array}{r}1 \\
\overline{-} \\
1 \overline{3} \\
- \\
\overline{-} \\
\overline{96} \\
\overline{-} \\
\overline{0} \\
10 \\
-\end{array}$ \\
\hline Total & 120 & 120 \\
\hline
\end{tabular}

TABLE 11

\begin{tabular}{l|c|c}
\hline & $\begin{array}{c}\text { Experimental } \\
\text { Classification }\end{array}$ & $\begin{array}{c}\text { Conventional } \\
\text { Classification }\end{array}$ \\
\hline Mean of deviations & +0.051 & +0.042 \\
Variance of deviations & 0.147 & 0.225 \\
\hline
\end{tabular}

$2 / 3$ and $3 / 2$ are given exactly two-thirds that weight ( $\frac{1}{4}$ of a unit on the scale) and those between readings of $0 /-$ and $1 / 2,1 /-$ and $2 / 3$, etc., are all given exactly fivethirds of that weight ( $\frac{5}{8}$ of a unit). There is no justification for assuming that these differences should be given these particular weights; indeed, there is some evidence that they should not. But, fortunately, the use of any more or less realistic scale leads to similar relativities of the variances of deviations (i.e. considerably lower variances for the experimental classification than for the conventional), while, throughout this experiment, the means of deviations were all small and showed no clear pattern.

It was clear that the variance (as obtained from any specific scale) was fairly closely related to the average amount of information. In any particular study (e.g. with any given reference reading) the relative merits of the two classifications always appeared the same whichever measure was adopted. Thus the average amount of information appears to provide at least as good an index of observer error as the use of the mean and variance of deviations. Further, as the amount of information is a "non-parametric" statistic, which does not depend on the doubtful assumptions implicit in the use of any scale, it is considered a preferable measure of observer error. 